\title{
A view from the trenches: what are the essential elements in the education of future physicians?*
}

M. Giger

\footnotetext{
* Modified opening address at the Annual Congress of the Association of Medical Education in Europe, Bern, $1^{\text {st }}$ September 2003.
}

Correspondence: Max Giger MD

Swiss Medical Association Department Medical Education

Elfenstrasse 18

CH-3000 Bern 16

\section{The future of medical education}

When we are asking for the essential elements in the education of future physicians we should ask what are the needs for the future patients.

\section{What is sure}

- The only sure epidemiologic notion is the augmentation of the oldest members in the society. We also have some knowledge about the prognosis of Alzheimer's disease, diabetes mellitus and morbid obesity.

- The European Working Time Directives will drive down the use of hospital beds mainly in the emergency sector. The EWTD will render the process of postgraduate training difficult, in the surgical disciplines restricting the total number of cases per trainee through shortening working and training times. This will result in a reduction in experience amongst trainees.

- Additionally, future patients will certainly wish for instant relief of symptoms. Their physicians have to be available 24 hours a day throughout the year including all holiday periods. There will be a further pressure to provide competent counselling, better guidance and quality of all medical solutions.

\section{What is probable}

- Health promotion in the industrialised countries perhaps can cut down the burden of alcoholism, dependence of tobacco abuse and immobility.

- Probably in the near future we will have to live with budgetary restrictions in the health sector and so we have to target on the really essential health needs. There is a European attitude to restrict governmental budgets. One of the most important targets is the containment of the social basket, and the consequence is governmental cost containment in the health sector.

- Through the use of targeting hospital beds to the real and essential medical needs and the further building of centres of excellence, the number of health personnel in the acute medicine sector could be reduced by one fifth.

- Economic restrictions will have an important effect on investment in medical education. There will be a strong demand for more efficiency in this field.

- Individual preferences in the health sector may change. There will be a further pressure to provide competent counselling, better guidance and quality of all medical services.

- Progression of the markets of wealth are body building and aesthetic surgery, and the wide field of complementary medicine.

\section{What are the opportunities}

- Medical progress: The future impact of genetics on diagnostics and remedies is tremendous. Effective targeting of pharmacotherapy to small patient groups may show the direction.

- Economic evolution: What impact will it have? Direction of funds to medical science?

- New diseases like the HIV pandemic and SARS: What risks will these produce?

- Progression of the antibiotic resistant strains of life threatening bacterial diseases: What risks will these produce?

\section{Swiss and European Reality}

The Swiss government is preparing new legislation for the education of medical professions. This new law should replace the law of 1877 , which was modified in the year 2000. This new law formulates the main targets for future physicians as follows:

- individual high quality patient care;

- social competency;

- reasoning and decision making on scientific, ethical and economical grounds;

- communication skills;

- knowledge of legislation. 
The quantity of physicians to be educated for future society depends on their actuary degree of medicalisation and their preference to invest in the sociomedical field. There are, in the main, no realistic guidelines to calculate the number of physicians needed. The stronger the governmental interventions are through the limitation of admission of young people to medical training, the more the same governments, 10-15 years later, have to correct inappropriate physician allocations. The right duration of medical education depends on the amount of learning objectives and the time needed to teach and learn. Few catalogues of learning objectives exist. In Switzerland such a catalogue will be applied in all five medical schools from autumn 2003. Unfortunately there exists no such catalogue for the postgraduate training in the 43 accredited specialities. In this field much hard work has to be done. In Switzerland the mean duration of graduate and postgraduate training is about 14-15 years. This educational time should be driven down to 11-12 years. This target can be attained through more efficiency of educational measures and better management mainly of the postgraduate training process. Continuing professional development is another high quoted item on the agenda of medical education. The Basel Declaration of the UEMS has to be applied in all European countries. The medical societies have to organise an independent efficient programme of Continuing Professional Development (CPD): The education has to be oriented to the needs of the daily medical work, it has to be independent of industrial and other sponsors. It has to be just in time, that means modern learning methods such as internet-based e-learning and blended learning, have to be used. In one sentence: Medical education must become more efficient and move into the $21^{\text {st }}$ century.

\section{Conclusion}

The essential elements for the education of future physicians can be deduced from the needs and wishes of future patients as follows:

- scientific reasoning (EBM);

- communication;

- humanities;

- responsibility;

- accountability;

- availability;

- networking;

- flexibility.

The goal of the education of future physicians is that they have knowledge, skills and attitude to practice an essential medicine for informed patients in a complex environment. 